\title{
ACIDENTES DO TRABALHO ENTRE TRABALHADORES DE ENFERMAGEM DE UM HOSPITAL UNIVERSITÁRIO*
}

\section{THE OCCURRENCE OF WORK ACCIDENTS AMONG NURSING PERSONNEL AT A UNIVERSITY HOSPITAL}

\author{
Maria Cecilia Cardoso Benatti**
}

BENATTI, MCC. Acidentes do trabalho entre trabalhadores de enfermagem de um hospital universitário. Rev Esc Enf USP, v. 35 , n. 2, p. 155-62, jun. 2001.

\section{RESUMO}

Foi realizado um estudo descritivo com trabalhadores de enfermagem para avaliar determinados aspectos epidemiológicos dos acidentes de trabalho acontecidos. No periodo de $1^{2}$ de janeiro a 30 de junho de 1995 foram estudados 100 acidentes do trabalho ocorridos, o que correspondem a 8,2\% de incidência acumulada no periodo para uma população de 1.218 trabalhadores pesquisados. Como sintese o estudo reconstroi o acidente do trabalho acontecido e os múltiplos fatores de risco presentes nas condições de trabalho de trabalhadores de enfermagem de um hospital universitário.

PALAVRAS-CHAVE: Acidentes do trabalho. Hospitais.

\begin{abstract}
A descriptive study was conducted to assess the epidemiological aspects of the work accidents that occur among nursing personnel. The study consisted of a population of 1,218 workers and assessed 100 accidents, that corresponded to $8.2 \%$ of all accidents that took place during the period, January 1" 1995 to June $3^{\text {th }} 1995$. The summary of this study evaluates the work accidents that occur among these nursing personnel and the risk factors presented by the working conditions of a university hospital.
\end{abstract}

KEYWORDS: Work accident. Hospitals.

\section{INTRODUÇÃO}

Nas instituições hospitalares brasileiras, os estudos sobre acidentes do trabalho, iniciados na década de 70 , necessitam ainda de abordagens mais aprofundadas.

$\mathrm{O}$ interesse pela questão do acidente do trabalho nos hospitais aumentou com o surgimento da Sindrome da Imunodeficiência Adquirida (AIDS) no início dos anos 80, com o temor do pessoal da saúde de contrair a doença em acidente com material potencialmente contaminado (BERGAMO; MARCELINO; GARRIDO, 1988; CARRASCAL, 1991; ROWE; GIUFFRE, 1991; YASSI; Mc, GILL, 1991; MACHADO et al., 1992).

$\mathrm{O}$ risco de contrair a AIDS somou-se aos grandes riscos já existentes no âmbito hospitalar que trazem danos potenciais ao pessoal que trabalha nele, entre os quais o da infecção hospitalar (CARVALHO; JALES, 1981; WAKAMATSU et al., 1986); o virus da hepatite B (FOCACCIA et al., 1986) e os acidentes radioativos (DAY, 1988).
Para agravar ainda mais os riscos que acometem o pessoal hospitalar, existe o fato de que o trabalhador no setor de saúde sofre as limitações impostas por suas próprias condições de vida e saúde (ALENCASTRE, 1983; NAKAO et al., 1986; FAVERO et al., 1987; PITTA, 1990).

Estudando a questão da saúde dos trabalhadores de um hospital geral de 400 leitos situado na área central do município de São Paulo, PITTA (1990) assim os caracterizou: pessoal essencialmente feminino $(68 \%)$ solteiro $(47 \%)$, branco $(64,9 \%)$, migrante $(69,4 \%)$, numa faixa etária entre 25 e 40 anos, tendo cursado, majoritariamente, até o primeiro grau e tendo renda per capita de até dois salários mínimos. Esses profissionais trabalham de dez a doze horas por dia em tarefas repetitivas; consideram o trabalho "insalubre e perigoso" e têm ou tiveram problemas

* $\quad$ Resultados parciais da tese de Doutorado - EEUSP/São Paulo - 1997

** Doutora em Enfermagem, especialista em Enfermagem do Trabalho, Professora Doutora do Departamento de Enfermagem da Faculdade de Ciências Médicas da Universidade Estadual de Campinas - e-mail: denffcm@fcm.unicamp.br • 
de saúde associados ao trabalho, em especial genitourinários $(60,1 \%)$, psicossomáticos $(14,6 \%)$ e osteomusculares $(6,9 \%)$.

Ponderando a respeito desses dados e considerando a importância do tema, justificou-se realizar este estudo no universo dos trabalhadores de enfermagem de um hospital universitário de grande porte do interior do Estado de São Paulo.

\section{OBJETIVO GERAL}

Avaliar determinados aspectos epidemiológicos dos acidentes do trabalho acontecidos.

\section{MATERIAL E MÉTODOS}

\section{1 Tipo de Estudo}

Estudo descritivo aplicado ao universo dos trabalhadores de enfermagem, acidentados no trabalho no primeiro semestre de 1995.

\subsection{População}

Foram entrevistados 100 acidentados do trabalho de uma população de 1218 trabalhadores (incidência acumulada de $8,2 \%$ de acidentes) no período analisado.

\subsection{Instrumento de Coleta de Dados}

Optou-se por uma entrevista estruturada utilizando formulário aplicado pela autora pessoalmente aos trabalhadores acidentados, a medida em que os acidentes foram ocorrendo.

\subsection{Aspectos Éticos}

A participação dos trabalhadores foi voluntária, autorizada pela instituição analisada e foi preservado o segredo quanto aos identificadores individuais. Respeitou-se o Código de Ética publicado pelo Conselho Federal de Enfermagem (1993) e que contém a Declaração de Helsinque.

\section{RESULTADOS E DISCUSSÃO}

A população estudada foi constituída por 100 trabalhadores de enfermagem que sofreram acidente do trabalho. Apenas três trabalhadores foram acidentados duas vezes no período e não se identificou nexo causal entre os acidentes seqüenciais.

A distribuição dos trabalhadores de enfermagem segundo o tipo de acidente ocorrido pode ser visualizado na tabela um.

Tabela 1 - Distribuição dos trabalhadores de enfermagem, acidentados do trabalho, segundo o tipo de acidente, Campinas, 1995.

\begin{tabular}{lcc}
\hline Tipo & \multicolumn{2}{c}{ Acidente } \\
\cline { 2 - 3 } & $\mathrm{N}^{\circ}$ & $\%$ \\
\hline Tipico & 89 & 89,0 \\
Trajeto & 11 & 11,0 \\
\hline Total & $\mathbf{1 0 0}$ & $\mathbf{1 0 0 , 0}$ \\
\hline
\end{tabular}

A distribuição dos casos por categoria profis-

sional potle ser observada examinando-se a tabela dois.
Tabela 2 - Distribuição dos trabalhadores de enfermagem, acidentados do trabalho, segundo categoria profissional, Campinas, 1995.

\begin{tabular}{llcc}
\hline \multirow{2}{*}{ Categoria profissional Trabalhadores Acidentados } \\
\cline { 2 - 4 } & $\mathrm{N}^{\circ}$ & $\mathrm{N}^{2}$ & $\%$ \\
\hline Técnico em enfermagem & 108 & 10 & 9,3 \\
Auxiliar de enfermagem & 614 & 53 & 8,6 \\
Enfermeiro & 298 & 23 & 7,7 \\
Atendente de enfermagem & 198 & 14 & 7,1 \\
\hline \multirow{2}{*}{ Total } & $\mathbf{1 . 2 1 8}$ & $\mathbf{1 0 0}$ & $\mathbf{8 , 2}$ \\
\hline
\end{tabular}

$\mathrm{Na}$ categoria profissional dos enfermeiros, ficou evidenciado (tabela dois) que os $7,7 \%$ acidentados não exercem cargos de direção, estando em sua totalidade em unidades de ambulatório ou de internação, exercendo funções assistenciais diretamente vinculadas ao atendimento dos pacientes.

Também foi constatado que os enfermeiros exercendo funções assistenciais foram acidentados praticamente nas mesmas proporções das outras categorias dos trabalhadores de enfermagem. Isso leva à suposição de que o conhecimento e o adestramento para o exercício de uma determinada função não são garantia de segurança no trabalho e que as condições perigosas e que provocam acidentes fogem ao controle do trabalhador independentemente de sua qualificação para o trabalho.

Quanto aos setores de trabalho do trabalhador acidentado, os dados obtidos podem ser observados examinando-se a tabela três.

Tabela 3 - Distribuição dos trabalhadores de enfermagem, acidentados do trabalho, segundo os setores de trabalho e categoria profissional, Campinas, 1995.

\begin{tabular}{|c|c|c|c|c|c|}
\hline \multirow{3}{*}{ Setor } & \multicolumn{5}{|c|}{ Categoria profissional } \\
\hline & \multicolumn{5}{|c|}{$\begin{array}{c}\text { Enf. Téc. } \\
\text { Aux. Atend. Total } \\
\end{array}$} \\
\hline & $\mathrm{N}^{\mathrm{O}}$ & $\mathrm{N}^{\circ}$ & $\mathrm{N}^{\mathrm{o}}$ & $\mathrm{N}^{\circ}$ & $\%$ \\
\hline Médico-cirúrgica I & 07 & 01 & 12 & 03 & 23,0 \\
\hline Centro cirúrgico & 01 & 02 & 14 & 02 & 19,0 \\
\hline Médico-cirúrgica II & 03 & 01 & 12 & - & 16,0 \\
\hline Retaguarda (trauma) & 03 & - & 04 & 01 & 8,0 \\
\hline Pediatria & 03 & 01 & 02 & 01 & 7,0 \\
\hline $\begin{array}{l}\text { Uníd. terapia intensiva } \\
\text { (UTI) }\end{array}$ & 02 & 01 & 03 & 01 & 7,0 \\
\hline Centro mat. esterilizado & 01 & 01 & 03 & 01 & 6,0 \\
\hline Pronto-socorro & 02 & 01 & 01 & 01 & 5,0 \\
\hline $\begin{array}{l}\text { Ambulatórios } \\
\text { especializados } \\
\text { Ambulatórios gerais }\end{array}$ & 01 & 02 & $\begin{array}{l}01 \\
01\end{array}$ & 03 & $\begin{array}{l}4,0 \\
4,0\end{array}$ \\
\hline Escolta pacientes & & & & 01 & 1,0 \\
\hline Total & 23 & 10 & 53 & 14 & 100,0 \\
\hline
\end{tabular}

Nas unidades em que se registraram os maiores indices de acidentes, o ritmo intenso de trabalho é um constante e o acidente pode ser conseqüência do

Em relação aos turnos de trabalho do trabalhador acidentado foram obtidos os seguintes resultados (tabela quatro) : 
Tabela 4 - Distribuição dos trabalhadores de enfermagem, acidentados no trabalho, segundo o turno e categoria profissional, Campinas, 1995.

\begin{tabular}{|c|c|c|c|c|c|c|c|c|c|}
\hline \multirow[t]{2}{*}{ Categoria } & \multicolumn{3}{|c|}{ Manhã } & \multicolumn{3}{|c|}{ Tarde } & \multicolumn{3}{|c|}{ Noturno } \\
\hline & Trab. & Ac. & trab. & Trab. & Ac. & trab. & Trab. & Ac. & trab. \\
\hline Profissional & N4 & N4 & $\%$ & NQ & N4 & $\%$ & $\mathrm{Ng}$ & N9 & $\%$ \\
\hline Enf. & 123 & 06 & 4,9 & 94 & 13 & 13,8 & 81 & 04 & 4,9 \\
\hline Téc. & 26 & 02 & 7,7 & 43 & 04 & 9,3 & 39 & 04 & 10,3 \\
\hline Aux. & 200 & 16 & 8,0 & 190 & 28 & 14,7 & 224 & 09 & 4,0 \\
\hline At. & 79 & 05 & 6,3 & 56 & 05 & 8,9 & 63 & 04 & 6,3 \\
\hline TOTAL & 428 & 29 & 6,8 & 383 & 50 & 13,1 & 407 & 21 & 5,2 \\
\hline
\end{tabular}

Pelo resultado da tabela quatro se verifica que o turno da tarde foi o de maior acidentalidade $(13,1 \%)$. Seguiu-se o turno da manhã $(6,8 \%)$ e por último o noturno $(5,2 \%)$. A significativa superioridade do turno da tarde sobre os da manhã e da noite também foi encontrada por SUBERO;

FERNANDEZ; CASTIEL (1987), na Espanha.

Dando seqüência à interpretação e análise dos resultados, procurou-se investigar o acidente acontecido, começando pela data da ocorrência (tabela 5).

Tabela 5 - Distribuição do acidente segundo o dia do mês da ocorrência, Campinas, 1995.

\begin{tabular}{ccc}
\hline $\begin{array}{c}\text { Dais do } \\
\text { mês }\end{array}$ & $\mathbf{N}^{\mathbf{0}}$ & \% \\
\hline 01 a 10 & 27 & 27,0 \\
11a20 & 35 & 35,0 \\
1 a 31 & 38 & 38,0 \\
\hline total & $\mathbf{1 0 0}$ & $\mathbf{1 0 0 , 0}$ \\
\hline
\end{tabular}

Analisando-se os dados da tabela cinco verifica-se ocorrência menor nos dez primeiros dias do mês (27\%).

A figura um apresenta a distribuição do acidente segundo o mês de

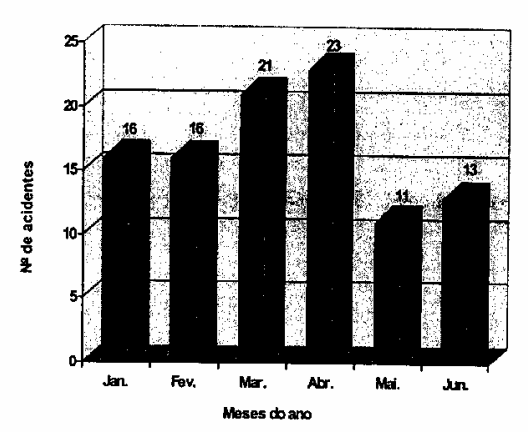

ocorrência

Figura 1 Distribuição do acidente segundo o mês (4,3\%). SANTOS et al. (1989) constataram aumento de ocorrência,
Campinas, 1995.

O mês de abril foi o de maior incidência, com $23 \%$, seguindo-se o de março, com 21\%. SILVA (1988) constatou o maior número de afastamentos por acidente no mês de maio $(10,7 \%)$.

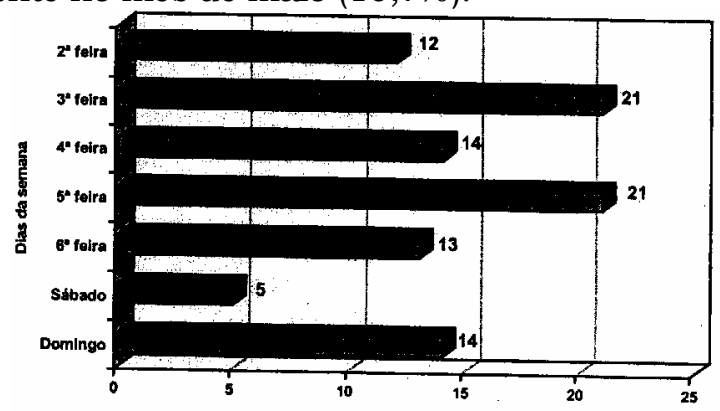

Os dias da semana em que ocorreram os acidentes podem ser visualizados na figura dois.

Figura 2 Distribuição do acidente segundo o dia da semana da ocorrência, Campinas, 1995.

A distribuição dos acidentes por dia da semana mostrou que a maioria se concentrou nos dias úteis, com picos nas terças e quintas-feiras.. A menor incidência deu-se no sábado (5\%). Esses dados parecem indicar o aumento (dias úteis) ou diminuição (fins de semana) do ritmo das atividades do hospital. O aumento do número de pacientes no domingo pode ser 10 explicado pela escassez de trabalhadores na escala, o

. Em trabalho anterior, BRANDI; BENATTI; ALEXANDRE (1998), no mesmo hospital, constataram o aumento dos acidentes por perfurcontantes nos dias úteis da semana. Os autores também verificaram que o número de acidentes no domingo $(8,7 \%)$ é o dobro doas acontecidos no sábado(4,1\%) 
As figuras três e quatro apresentam, respecti- transcorrido após a entrada do trabalhador em serviço. vamente, o horário de ocorrência do acidente e o tempo

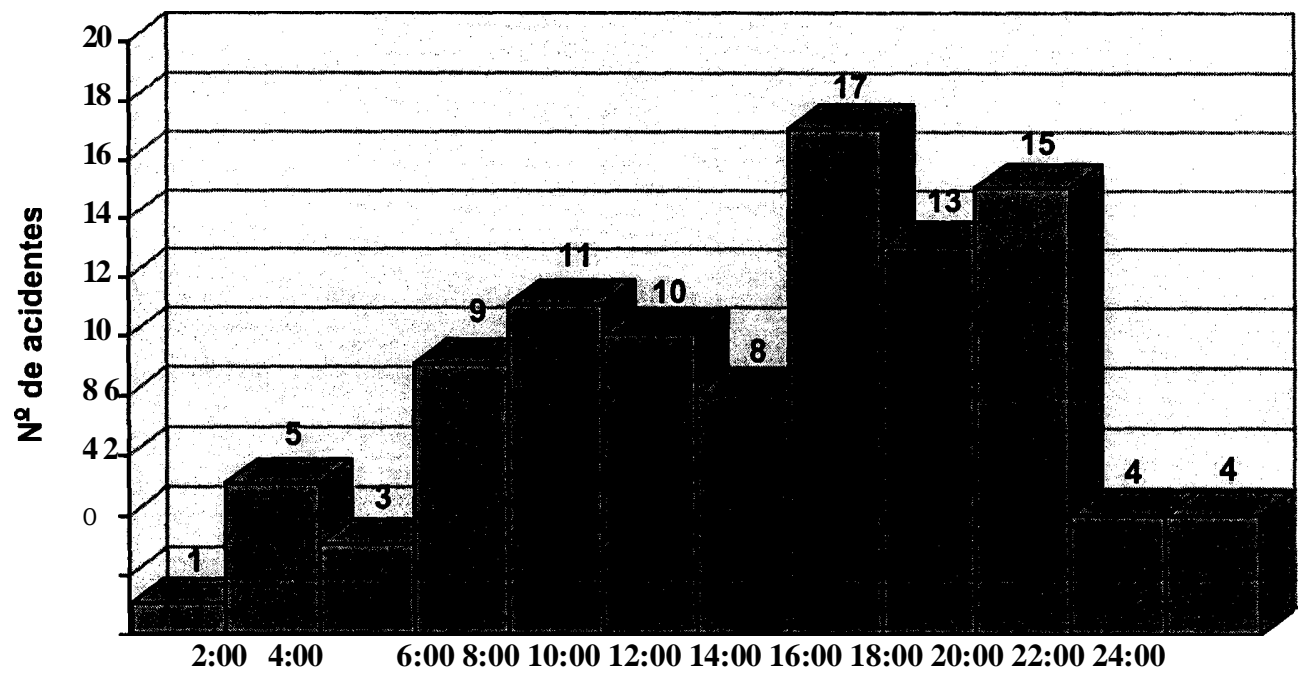

Horário

Figura 3 - Distribuição do acidente segundo o horário da ocorrência, Campinas, 1995.

Esse dado vem confirmar os achados de SILVA relacionada com os periodos do dia em que ocorre o maior (1988) e BRANDI; BENATTI; ALEXANDRE (1998), que número de atividades desenvolvidas pelos trabalhadores demonstrara que a maior ocorrência de acidentes está de enfermagem, ou seja, o periodo diurno.

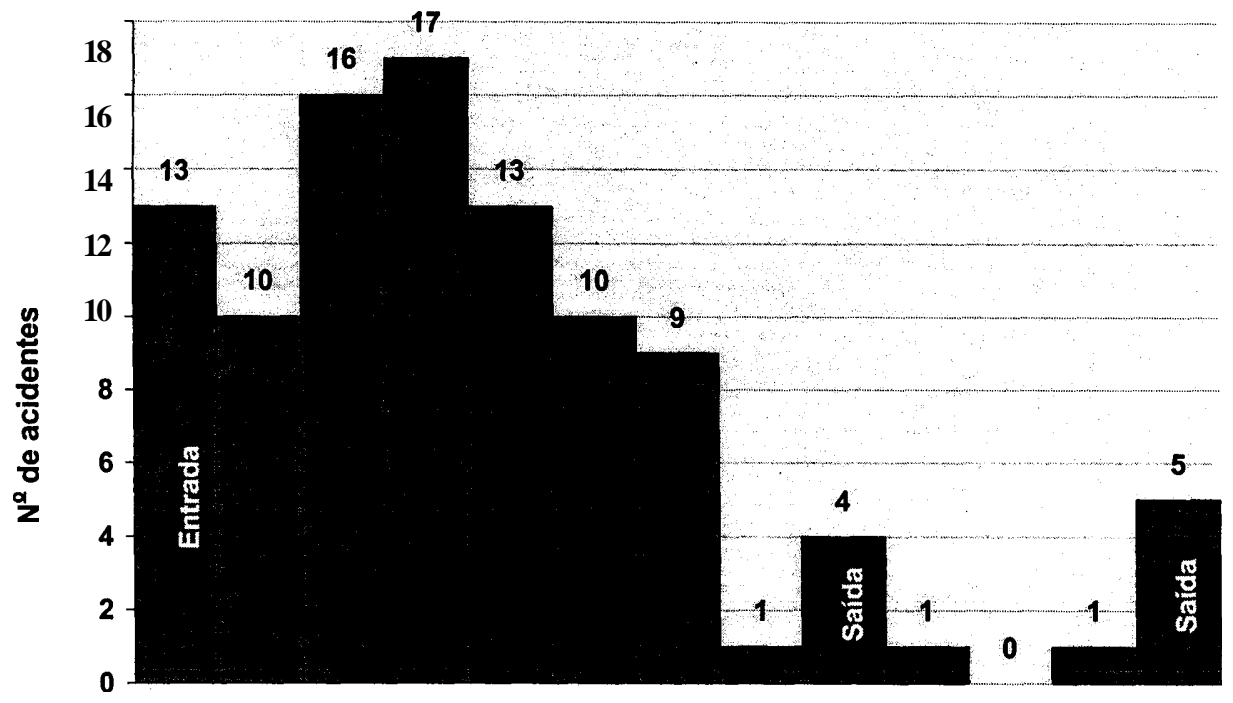

$1: 00 \quad 2: 003: 00 \quad 4: 005: 00 \quad 6: 00$ 7:00 8:00 9:00 10:00 11:00 12:00

Horas trabalhadas

\section{Figura 4 - Distribuição do acidente segundo o tempo decorrido em relação ao inicio da jornada de} trabalho, Campinas, 1995.

Pela figura quatro se observa que o maior número de acidentes ocorreu entre a entrada do trabalhador e a sétima hora de trabalho. Os acidentes ocorridos entre a nona e a $12^{\circ}$ se deram com os trabalhadores do turno da noite, cuja jornada é de 12 x 36 horas.

Os acidentes acontecidos na entrada e saida dos trabalhadores somam $22 \%$ do total. Desses, $11 \%$ foram
Acidentes de trajeto, $7 \%$ foram acidentes nos pátios ou corredores internos do hospital e $4 \%$ ocorreram nas unidades de trabalho.

Pela análise da figura quatro pode-se supor que são o ritmo e as condições de trabalho que submetem o trabalhador hospitalar ao risco do acidente, já que a grande maioria dos acidentes aconteceu ao longo de toda a jornada, mostrando-se com padrões próximos 
nas primeiras horas, no meio da jornada e nas últimas horas do trabalho. Foram encontrados dados semelhantes no estudo de SANTOS et al (1989).

Continuando a análise do acidente, procurouse investigar o local da ocorrência (tabela seis).

Tabela 6 - Distribuição do acidente segundo o local da ocorrência. Campinas, 1995.

\begin{tabular}{lll}
\hline \multicolumn{1}{c}{ Local } & $\mathbf{N}^{\circ}$ & \\
\hline Unidade de trabalho & 78 & 78,0 \\
Trajeto & 11 & 11,0 \\
Corredor interno HC & 08 & 8,0 \\
Pátio externo HC & 03 & 3,0 \\
\hline Total & $\mathbf{1 0 0}$ & $\mathbf{1 0 0 , 0}$ \\
\hline
\end{tabular}

Pela tabela seis verifica-se que $78 \%$ dos acidentes ocorreram durante o processo de trabalho, no desenvolvimento de atividade de cuidado ao paciente. A tabela sete apresenta em mais detalhes os acidentes segundo o local de ocorrência na unidade de trabalho.
Tabela 7 - Distribuição do acidente segundo a localização na unidade de trabalho, Campinas, 1995.

\begin{tabular}{lll}
\hline \multicolumn{1}{c}{ Unidade de trabalho } & $\mathrm{N}^{\circ}$ & $\%$ \\
\hline Quarto-leito & 22 & 22,0 \\
Expurgo & 13 & 13,0 \\
Posto enfermagem & 12 & 12,0 \\
Boxe-leito, maca & 09 & 9,0 \\
Sala operação & 08 & 8,0 \\
Corredor interno & 07 & 7,0 \\
Quarto-sanitário & 02 & 2,0 \\
Patologia-necrotério & 02 & 2,0 \\
Capela de quimioterapia & 01 & 1,0 \\
Consultório & 01 & 1,0 \\
Local inespecifico & 01 & 1,0 \\
\hline Total & $\mathbf{7 8}$ & $\mathbf{7 8 , 0}$ \\
\hline
\end{tabular}

A análise do acidente do trabalho acontecido, no que se refere à causa ou ao objeto causador do acidente, remete, por sua importância, aos acidentes ocasionados por agulhas e por outros objetos cortantes, como lâminas, seringas e tesouras (tabela oito).

Tabela 8 - Distribuição do acidente com material perfurocortante, segundo o objeto causador, Campinas, 1995.

\begin{tabular}{|c|c|c|c|c|c|}
\hline Perfurante & $\mathbf{N}^{\circ}$ & $\%$ & Cortante & $\mathbf{N}^{2}$ & $\%$ \\
\hline Agulha injeção & 14 & 34,0 & Lâmina bisturi & 12 & 29,3 \\
\hline Agulha abocath & 03 & 7,3 & Lâmina barbear & 01 & 2,4 \\
\hline Agulha sutura & 03 & 7,3 & Abridor frasco & 01 & 2,4 \\
\hline Agulha vacutainer & 02 & 4,9 & Tesoura cirúrgica & 01 & 2,4 \\
\hline Agulha biópsia/punção & 01 & 2,4 & Seringa vidro & 01 & 2,4 \\
\hline Agulha intracath & 01 & 2,4 & & & \\
\hline Agulha scalp & 01 & 2,4 & & & \\
\hline Total & 25 & 61,0 & Total & 16 & 39,0 \\
\hline
\end{tabular}

Nos estudos de SANTOS; PELA (1989), SANTOS et al. (1989); SOUZA; VIANA (1993); e SILVA et al. (1995), o acidente perfurocortante também foi a primeira causa de acidente.

Em pesquisa anterior a esta e com dados colhidos em 1994, já haviam sido encontrados no mesmo hospital 46 acidentes com material perfurocortante. Uma análise comparativa mostra que os dados nos dois estudos se aproximam em resultados, já que os maiores índices de acidentes no primeiro estudo também foram por agulha e lâmina de bisturi (BRANDI; BENATTI; ALEXANDRE, 1998).

Em relação às atividades que os trabalhadores de enfermagem estavam executando no momento do acidente com material perfurocortante, foram encontrados os seguintes dados (tabela nove).
Tabela 9 - Distribuição das atividades relacionadas com o acidente com material perfurocortante, Campinas, 1995.

\section{Atividade / causa}

\begin{tabular}{lll}
\hline Agulha ou lâmina abandonada no ambiente & $\mathbf{N}$ & $\mathbf{\%}$ \\
\hline Abrindo frasco ou ampola & 10 & 10,0 \\
Tentativa de punção venosa & 08 & 8,0 \\
Lavando material no expurgo & 05 & 5,0 \\
Desencapando ou reencapando agulha Cortando & 04 & 4,0 \\
esparadrapo ou micropore (c/ lâmina) & 04 & 4,0 \\
Descartando agulha caixa cortante & 03 & 3,0 \\
Perfurando tampa tubo ou soro & 03 & 3,0 \\
Movimentando paciente leito & 02 & 2,0 \\
Insuflando balão sonda vesical & 01 & 1,0 \\
& 01 & 1,0 \\
\hline Total & $\mathbf{4 1}$ & $\mathbf{4 1 , 0}$ \\
\hline
\end{tabular}

Observando-se a tabela nove, constata-se o uso abusivo de lâminas em atividades não necessárias e o abandono de material descartável, após uso, em lugares inadequados (balcões, bandejas, camas, pisos).

Dando prosseguimento à análise, foram estudados os demais acidentes por outras causas (tabela dez). 
Tabela 10 - Distribuição do acidente segundo a causa

ou o obieto causador. Campinas, 1995.
Tabela 12 - Distribuição do acidente segundo o diagnóstico da lesão, Campinas, 1995.

\begin{tabular}{|c|c|c|c|c|c|}
\hline Causa / objeto causador & N9 & $\%$ & Diagnóstico & N9 & $\%$ \\
\hline Material perfurocortante & 41 & 41,0 & Ferimento perfurante & 25 & 19,7 \\
\hline Contato com fluido corporal (pele, olhos) & 12 & 12,0 & Cervicodorsolombalgia & 21 & 16,5 \\
\hline Queda ao solo/ escorregão/ torção & 12 & 12,0 & Abrasão, contusão, escoriação & 15 & 11,8 \\
\hline Acidente de trânsito (incl. queda coletivo) & 09 & 9,0 & Contaminação biológica & 13 & 10,2 \\
\hline Carregamento peso excessivo & 06 & 6,0 & Trauma ocular (incl. corpo estranho) & 11 & 8,7 \\
\hline Esforço físico/ postura não ergonômica & 04 & 4,0 & Ferimento cortante sem sutura & 10 & 7,9 \\
\hline Contato com solução químíca & 03 & 3,0 & Ferimento cortante com sutura & 06 & 4,7 \\
\hline Impacto contra objeto & 03 & $\mathbf{3 , 0}$ & Efeito tóxíco por agente químico & 05 & 3,9 \\
\hline Agressão de paciente & 02 & 2,0 & Politraumatismo com lesão craniana & 06 & 3,9 \\
\hline Contato com quimioterápico & 02 & 2,0 & Distensão, entorse, luxação com fratura & 04 & 3,1 \\
\hline Impacto por queda objeto & 02 & 2,0 & Distensão, entorse, luxação sem fratura & 03 & 2,4 \\
\hline Queda com diferença nivel (buraco) & 02 & 2,0 & Lesão por esforço repetitivo (L.E.R.) & 03 & 2,4 \\
\hline Contato com látex luva & 01 & 1,0 & Queimadura de primeiro grau & 03 & 2,4 \\
\hline \multirow[t]{2}{*}{ Contato com objeto quente } & 01 & 1,0 & Politraumatismo sem lesão craniana & 02 & 1,6 \\
\hline & & & Dermatite de contato & 01 & 0,8 \\
\hline \multirow[t]{2}{*}{ Total } & 100 & 100,0 & & & \\
\hline & & & Total & 127 & 100,0 \\
\hline
\end{tabular}

As causas demonstradas na tabela dez sugerem que parcela significativa dos acidentes com trabalhadores de enfermagem não é específica da área hospitalar, sendo os acidentes similares aos que ocorrem na indústria: queda, queimaduras, carregamento de peso excessivo e outros.

Após o estudo da causa ou do objeto causador da lesão, foi analisado a região anatômica atingida pelo acidente (tabela onze).

Tabela 11- Distribuição do acidente segundo a região corporal da lesão, Campinas, 1995.

\begin{tabular}{lcc}
\hline Região corporal da lesão & $\mathrm{N}^{\circ}$ & $\%$ \\
\hline Membros superiores & $\mathbf{9 7}$ & $\mathbf{4 9 , 7}$ \\
Membros inferiores & $\mathbf{4 0}$ & $\mathbf{2 0 , 5}$ \\
Tronco (incluindo pescoço) & $\mathbf{3 0}$ & $\mathbf{1 5 , 4}$ \\
Cabeça & 28 & $\mathbf{1 4 , 4}$ \\
\hline Total & 195 & $\mathbf{1 0 0 , 0}$ \\
\hline
\end{tabular}

Nota: uma ou mais região corporal por trabalhador.

Foi encontrada freqüentemente mais de uma região corporal (atingida pelo acidente) por trabalhador. As lesões dos membros superiores foram as mais encontradas (49,7\%). SILVA (1988) obteve dados semelhantes $(49,5 \%)$. Também para MONTEIRO; CARNIO; ALEXANDRE (1987), SANTOS; PELA (1989) e SANTOS et al. (1989), os membros superiores, em especial mão-dedos, foram os mais atingidos.

$\mathrm{Na}$ análise do acidente do trabalho é muito importante o estudo do diagnóstico provável ou da natureza clínica da lesão (tabela doze).
Nota: um ou mais diagnóstico por trabalhador.

Pesquisas que enfocam o acidente do trabalho em trabalhadores de enfermagem têm demonstrado que a maior freqüência, logo após as lesões perfurocortantes, são as referentes ao sistema osteoarticular, destacando-se entre essas as que comprometem a coluna vertebral (SANTOS; PELA, 1989; SANTOS et al. 1989 e SILVA et al. 1995).

Tendo-se perguntado aos trabalhadores sobre se no momento do acidente havia sobrecarga de trabalho, 49\% responderam que não e $37 \%$ responderam que sim. Os restantes $14 \%$ foram acidentes acontecidos extra-hospital.

Os trabalhadores acidentados atribuiram o acidente à fatalidade, ao azar, "tinha qué acontecer" (34\%), às condições de trabalho (30\%) e à sua própria culpa (14\%). Os $22 \%$ restantes atribuíram o acidente a outros motivos.

Para 30\% dos trabalhadores acidentados, a culpabilidade pelo acidente foi das condições de trabalho. Mesmo quando são conhecidas as más condições de trabalho, inclusive pela existência de outros acidentes anteriores no mesmo local, o trabalhador não questiona a periculosidade a que está exposto. Nesta pesquisa, 6\% dos acidentes ocorreram no expurgo da Central de Material Esterilizado. Quando questionada, a trabalhadora respondeu que o acidente foi ocasionado pelo "próprio risco existente no expurgo da Central de Material". Na Psiquiatria, os acidentados foram agredidos pelos pacientes e, quando entrevistados, responderam que isso se deveu ao "próprio risco de trabalhar com paciente psiquiátrico" e "o paciente estava em delírio".

Embora reconhecendo as condições de trabalho como causa de seu acidente, os trabalhadores não dão o passo seguinte que seria questionar a organização do trabalho (hospital) quanto à periculosidade exis- 
tente e aos motivos que geraram os infortúnios. Estes se apresentam para eles como algo natural, fatal e inevitável.

Quanto às conseqüências do acidente, $55 \%$ dos entrevistados afirmaram ainda estar sofrendo um ou mais sintomas físicos ou psíquicos (figura 5).

\begin{tabular}{|c|l|}
\hline $\begin{array}{c}\mathbf{N}^{\circ} \mathbf{d e} \\
\text { casos }\end{array}$ & \multicolumn{1}{|c|}{ Sintomas } \\
\hline 28 & Edema e dor \\
\hline 14 & Preocupação com HIV e hepatite \\
\hline 07 & Controle sangue (HIV) \\
\hline 04 & Licença médica (coluna e L.E.R.) \\
\hline 03 & Crises emocionais \\
\hline 03 & Lesão por esforço repetítivo (L.E.R.) \\
\hline 02 & Dor por acidente do trabalho anterior \\
\hline 02 & Opacidade da córnea \\
\hline 02 & Perestesia e quelóide \\
\hline 01 & Cirurgia marcada (ombro) \\
\hline 01 & Dermatite de contato \\
\hline 01 & Foco cerebral (desmaio, cefaléia) \\
\hline 01 & Processo infeccioso (dedo) \\
\hline
\end{tabular}

Figura 5 - Sintomas alegados pelos trabalhadores acidentados e ainda presentes no momento da entrevista, Campinas, 1995.

\section{CONSIDERAÇÕES FINAIS}

O acidente do trabalho hospitalar está se tornando cada vez mais uma preocupação para os administradores hospitalares, pois além de gerar prejuízos para a saúde dos trabalhadores envolvidos onera o hospital de diversas maneiras principalmente pelo afastamento do trabalhador de seu posto de trabalho.

No presente estudo após oito meses de coleta de dados encerrada constatou-se:

- Sete trabalhadores ainda em observação por contaminação com perfurocortante;

- Dois trabalhadores em licença-médica, um por contaminação biológica (abscesso em dedo) e outro por acidente de trajeto (politraumatismo com lesão intracraniana);

- $\quad$ Oito trabalhadores em fase de observação ou de diagnóstico já confirmado de doença relacionada com o trabalho (quatro em licença-médica). Destes, cinco casos com diagnóstico de lesão da coluna cervical e três casos de L.E.R./DORT.

\section{Com base nestes resultados, sugere-se:}

- Ampliar ações preventivas e coletivas, tornando mínimos os fatores de risco que possam dar origem aos acidentes do trabalho;

- Efetuar campanhas de vacinação para obter oíndice cada vez mais elevado de imunizados;

- Resgatar e valorizar o saber acumulado pelos O acidente também foi investigado quanto a suatrabalhadores sobre o seu trabalho, sobre os riscos notificação por meio da comunicação de acidente dopresentes em seu cotidiano e as repercussões dos trabalho - CAT (tabela treze). mesmos sobre sua saúde.

Tabela 13 - Distribuição do acidente segundo a notificação, Campinas, 1995.

\section{REFERÊNCIAS BIBLIOGRÁFICAS}

\begin{tabular}{lcccccc}
\hline \multirow{2}{*}{$\begin{array}{c}\text { Acidente do } \\
\text { trabalho }\end{array}$} & \multicolumn{2}{c}{ UNICAMP } & \multicolumn{2}{c}{ FUNCAMP } & \multicolumn{2}{c}{ Total } \\
\cline { 2 - 7 } & $\mathrm{N}^{\circ}$ & $\mathbf{\%}$ & $\mathrm{NQ}$ & $\mathbf{\%}$ & $\mathbf{N}^{\circ}$ & $\%$ \\
\cline { 2 - 7 } Notificado & 33 & 61,1 & 15 & 36,6 & 48 & 50,5 \\
Não notificado & 21 & 38,9 & 26 & 63,4 & 47 & 49,5 \\
\hline Total & $\mathbf{5 4}$ & $\mathbf{1 0 0 , 0}$ & $\mathbf{4 1}$ & $\mathbf{1 0 0 , 0}$ & $\mathbf{9 5}$ & $\mathbf{1 0 0 , 0}$ \\
\hline
\end{tabular}

ALENCASTRE, MB. As condições sócio-econômico-sanitárias do atendente psiquiátrico e sua relação com o trabalho que executa. Rev Bras Saúde Ocup, v.11, n.42, p.27-9, 1983.

BERGAMO, M; MARCELINO, K; GARRIDO, LS. Procedimentos técnicos básicos na prevenção da "AIDS" num centro cirúrgíco de grande porte. Rev Bras Enf, v.41, n.2, p.155-60, 1988.

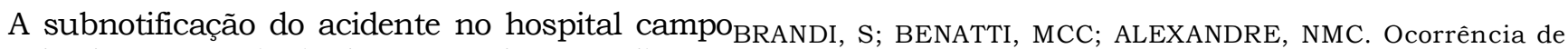
de estudo deveu-se principalmente a descentralizaçãoacidente do trabalho por material perfuro cortante entre da notificação pelo campus da UNICAMP Em váriostrabalhadores de enfermagem de um hospital universitário da casos, os trabalhadores não sabiam onde notificar o cidade de Campinas, Estado de São Paulo. Rev Esc Enf USP, v.32,

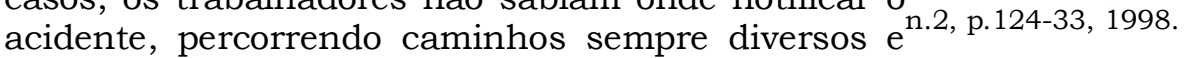
muitas vezes interrompendo a notificação em face das dificuldades deparadas em seu percurso. 
CARVALHO, JPP; JALES, LS. Acidentes envolvendo riscos biológicos e infecções associados a trabalhos de laboratório. Rev Bras Saúde Ocup, v.9, n.35, p.19-24, 1981.

CONSELHO FEDERAL DE ENFERMAGEM. Código de Ética: profissionais de enfermagem. Rio de Janeiro: 1993.

DAY, J. Peligros de la radiación. Rev Rol Enf, v.11, n.116, p.811, 1988. Suplemento.

FÁVERO, $\mathrm{N}$ et al. Estudo do grau de satisfação e cansaço dos funcionários do serviço de enfermagem que trabalham concomitantemente em duas instituições hospitalares. Rev Paul Hosp, v.35, n.4/6, p.51-5, 1987.

FOCACCIA, $\mathrm{R}$ et al. Risco de contágio pelo virus da hepatite $\mathrm{B}$ em funcionários hospitalares e imunidade naturalmente adquirida. Rev Assoc Med Bras, v.32, n.7/8, p.111-4, 1986.

MACHADO, AA et al. Riscos de infeccão pelo vírus da imunodeficiência humana (HIV) em profissionais da saúde. Rev Saúde Públ, v.26, n.1, p.54-6, 1992.

MONTEIRO, MS; CARNIO, AM; ALEXANDRE, NMC Acidentes de trabalho entre o pessoal de enfermagem de um hospital universitário. Rev Bras Enf, v.40, n.2/3, p.89-92, 1987.

NAKAO, JRS et al. Análise dos fatores que contribuem para que funcionários do serviço de enfermagem trabalhem em duas instituições hospitalares. Rev Paul Enf, v.6, n.2, p.78-82, 1986.

PITTA, AMF Hospital: dor e morte como oficio. São Paulo: Hucitec, 1990

ROWE, PM; GIUFFRE, M. Evaluating needlestick injuries in nursing personnel. AAOHN $\boldsymbol{J}$, v.39, n.11, p.503-7 1991

SANTOS, WDF; PELA, NTR. Acidentes típicos de trabalho em pessoal de enfermagem de unidades cirúrgicas. In: JORNADA DE ENFERMAGEM EM CENTRO CIRÚRGICO DO ESTADO DE SÃO PAULO, 3, Ribeirão Preto, 1989. Anais. Ribeirão Preto: Sociedade Brasileira de Enfermagem de Centro Cirúrgico, 1989. p.433-42.
SANTOS, WDF et ai. Acidentes típicos de trabalho em pessoal de enfermagem: fatores associados, Rev Bras Saúde Ocup, v.17, n.68, p.38-42, 1989,

SILVA, A et al. Estudo sobre os acidentes de trabalho ocorridos com a equipe de enfermagem em unidade de centro cirúrgico de um hospital geral: São Paulo. In: CONGRESSO BRASILEIRO DE ENFERMAGEM EM CENTRO CIRÚRGICO, 2, São Paulo, 1995. Anais. São Paulo, Sociedade Brasileira de Enfermagem de Centro Cirúrgico, 1995. p. 94-102.

SILVA, VEF. Estudo sobre acidentes de trabalho ocorridos com trabalhadores de enfermagem de um hospital de ensino. São Paulo, 1988. 176p. Dissertação (Mestrado) - Escola de Enfermagem, Universidade de São Paulo.

SOUZA, M; VIANNA, LAC. Incidência de acidentes de trabalho relacionada com a não utilização das precauções universais. Rev Bras Enf, v.46, n.3/4, p.234-44, 1993.

SUBERO, RC; FERNANDEZ, FC; CASTIEL, JF. A acidentalidade laboral em um hospital geral. Saúde Trabalho, v.1, n.3, p.176-81, 1987.

WAKAMATSU, CÁ et al. Riscos de insalubridade para o pessoal de hospital. Rev Bras Saúde Ocup, v.14, n.53, p.52-60, 1986.

YASSI, A; Mc GILL, M. Determinants of blood and body fluid exposure in a large teaching hospital: hazards of the intermittent intravenous procedure. Am J Infect Control, v.19, n.3, p.12935, 1991, 